\title{
Family reactions and their management in a parents group with beta-thalassaemia
}

\author{
J TSIANTIS, D XYPOLITA-TSANTILI, AND S PAPADAKOU-LAGOYIANNI
}

Department of Psychological Paediatrics and Department of Paediatrics, Aghia Sophia Children's Hospital, Athens, Greece

SUMMARY The parents of children with $\beta$-thalassaemia displayed various patterns of emotion (guilt, death anxiety, denial of feelings) and their behaviour towards the child was inappropriate (overprotective, conspiracy of silence); this could affect his psychosocial development and lead to tension within the family. Some parents were overdemanding and even hostile to hospital staff, thus making the management of cases difficult. The therapeutic team has tried to concentrate on these problems in order to clarify them and give support to the families. This has facilitated communication within the family as well as between the family and hospital staff, and has diminished the problems.

The child with $\beta$-thalassaemia is a chronically sick child who suffers from a severe chronic haemolytic anaemia necessitating treatment with transfusions for survival; his illness is a source of chronic stress to himself, to his parents, and to the rest of his family.

It is estimated that scattered throughout Greece there are about 3000 families with children with $\beta$-thalassaemia. This constitutes a sizeable problem for the medical and psychosocial services ( $\mathrm{Ch}$ Kattamis, 1981, personal communication).

The chronically sick child and his family are likely to be affected psychologically. ${ }^{1-5}$ Anxiety about the illness may lead to restriction of some of the child's normal activities and prevent him from making friends. The parents' attitude may result in over-protective behaviour or in open rejection. The child's own feelings and reactions to his illness may affect his relationship with his siblings, with other adults, or with his parents.

The prognosis for thalassaemic patients has now improved. This has been brought about by the application of frequent transfusions and, especially, by the early introduction and regular use of ironchelating agents, and by the prevention of hemosiderosis. Consequently the average life expectancy for children has increased. Generally, the modern treatment and management of the disease has reduced the number of complications, the need for admission to hospital, and the time spent there. However, the treatment of such children is mainly on an outpatient or a day unit basis. The improvement in the prognosis of the disease has started gradually to affect the attitude of those concerned with the thalassaemic child, although it seems that $\beta$-thalassaemia is still considered to be a fatal disease.

Experience in the transfusion clinic at Aghia Sophia Children's Hospital where children who suffer from $\beta$-thalassaemia receive regular transfusions has shown the need for psychological support and management of the whole family of the sick child. We therefore initiated a programme using group therapy with the parents of children with $\beta$-thalassaemia. The aims of the programme were: (1) to demonstrate more explicitly the psychological burden that many families with $\beta$-thalassaemia experience; (2) to support and relieve, as far as possible, some of the families; (3) to develop a working scheme-a kind of liaison psychiatry-with the medical and nursing staff working with these families, aimed at increasing awareness of the psychological aspects of the problem; (4) to establish the scope and purpose of a more systematic research study on the psychosocial problems generated by the child and his family.

\section{Method and sample}

The original sample comprised 15 families, each with one child with $\beta$-thalassaemia. Such children were attending the outpatient transfusion department at least once a month. The families were chosen on the basis of their keeness to attend and their need for help. The multi-disciplinary team included a child psychiatrist, a psychiatric social worker, and a paediatrician.

The parents and the team met once a fortnight for a year, and then, in response to parents for more 
meetings, weekly for 2 years. The meetings generally lasted 2 hours. By the end of this 3-year period the original group of parents had more or less been replaced by others. The group discussions were generally attended by mothers but sometimes fathers came too.

Observations from the group work. The following four clusters of feelings and behavioural patterns were noted in the parents.

\begin{abstract}
Depression
Depression was generally masked, but sometimes overt. It is known that guilt accompanies depressive feelings but the guilt in these cases was strong and associated with self blame. Self blame was associated with the hereditary nature of the illness and the fact that the parents had transmitted the illness to the child. Such depressive reactions were prolonged and difficult to alleviate. Parents accused themselves incessantly and felt inescapably 'omnipotent' with regard to their own 'bad' and 'poisonous' blood which they had transmitted to their children.

In some these depressive feelings were intense and seemed related to the parents' own ambivalent feelings about the child and to previous experiences - such as a previous death or early deprivation. In nearly every case the parents had not known that they were carriers of the trait.
\end{abstract}

\section{Death anxiety}

This was a prominent and recurrent subject in all the discussions. Anxiety about death is common in parents with a chronically sick child, but it was clear from these parents that such anxiety and fear of death was linked with the life expectancy of the child.

It is interesting that even though the parents knew about the recent improvements in the prognosis, they still remained preoccupied with death. However a change in attitude is a slow process. We speculated that in a few cases death anxiety was associated with deeper psychological problems that could not be explored in the group.

\section{Denial of the problem and feelings}

Denial was shown by a number of parents. Some parents could not come to terms with the reality of the child's illness and denied it altogether. It was as if the illness was a blow to their narcissistic needs and consequently to their self-image as good parents. The denial was in some cases an attempt to cover unconscious hostility towards and rejection of the child. Social factors were also concerned in the mechanisms of denial. These parents felt that a sick child was a demonstration of their failure, so that they were ashamed and tried even more vigorously to deny that there was anything wrong with the child.

\section{Conspiracy of silence}

This describes the situation whereby nearly everybody in the family, even the sick child, knew about the illness; they all experienced the burden of it, but nobody talked openly about it within the family. It seemed to be related with the average life expectancy of the child as well as with other emotionally-charged situations-such as the frequent transfusions and the blood tests, the frequency of past complications leading to admission to hospital, and the sacrifices that the rest of the family had made for the sick child. In families with older children the parents' dilemma was particularly difficult, because the children were likely to ask questions about the illness including its hereditary nature. The main factor that blocked the intrafamily communications seemed to be related to the hereditary nature of the condition. Often the children wanted to ask questions about the illness and to discuss their feelings and worries about it, but attempts were blocked by the half-truths and evasive answers that they received. Sometimes children themselves preferred not to ask, as a defensive mechanism.

Such behavioural patterns and emotional manifestations can affect the child in several ways. For example, the depression, guilt, and anxiety about death often forced the parents to be overprotective. They were unable to set limits and ended up by spoiling the child. Expectations from the child were also low. Obviously the emotional atmosphere and the care the child received did not help his psychosocial development, and he remained immature and dependent on his parents; his socialisation was inadequate or defective, and academic achievement was quite often affected too. Denial of the problem and their attitude to it made some parents overambitious for their child to succeed academically at school or to excel at sports. Such ambitions forced the child to deny his problems in an attempt to please. It also led to an emotional isolation and alienation because the child needed desperately to talk with his parents about his feelings. Furthermore, he needed to know the truth about what was wrong with him. The child's isolation was made greater by the conspiracy of silence that blurred all communications. Paediatricians and nursing staff often found themselves unwilling participants in this conspiracy of silence.

These behavioural patterns and intrafamily relationships alternate from one to the other, and siblings and members of the extended family were often affected as well, leading to a vicious circle (Figure). 


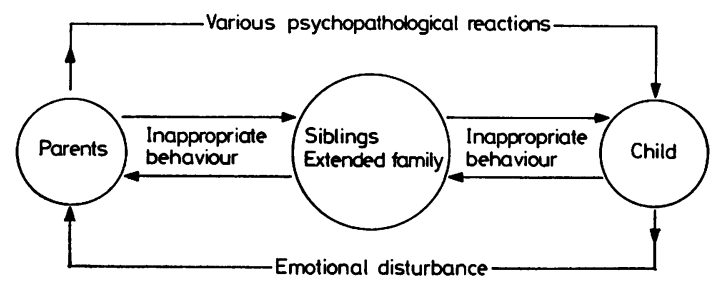

Figure Vicious circle of behavioural pattern.

The family's relationship with the rest of the community was affected, and the family tended to be socially isolated. They felt ashamed of the child's condition and guilty about having transmitted the trait (or stigma*) that was equivalent to a social 'stigma'. Parents often expressed strong feelings about the child's lack of colour or the other abnormalities that are characteristic of the condition, especially if the affected child was a girl. Facial abnormalities were another factor that prompted the family to 'hide' the child for social reasons.

Problems also arose with the child's school. The children were often away from school and parents revealed in the group discussions that they did not want to explain to the teacher the reasons for the absence. Some had even asked the child to lie to the teacher, thus generating conflict within the child. Apparently this transaction is another manifestation of the conspiracy of silence and it illustrates the kind of double-blind situation the child is in.

Inevitably the medical and nursing staff who were working with these families were bound to find themselves in an emotionally-charged situation. The needs of these families were excessive. Anxiety and depression may permeate within a ward or within an outpatient transfusion department. Parents often projected their anger and guilt on to the medical and nursing staff and criticised the management of their children. Others tended to project their omnipotent feelings on to medical and nursing staff and expected 'magic cures', or blamed the doctors or nurses if something went wrong with the child. It is clearly easy to create problems in the management of such cases, and they can be particularly intense if the nursing and medical staff are not aware of the complexities of the parental feelings, and the reactions and conflicts that can be generated within themselves. Factors that also affected the management of the children were frequent staff changes (these disturb parents and children for obvious reasons), staff overburdened with work, and unsuitable layout of the transfusion department-such as lack of space and shortage of play areas.

* In Greek the word stigma means trait.

\section{Modes of intervention}

The group discussions enabled parents: (1) To identify the psychological problems generated in the family from the chronicity of the illness. (2) To meet other parents and exchange and share experiences and feelings. (3) To draw attention to inappropriate emotional reactions and clarify them. (4) To give information on the current knowledge of $\beta$ thalassaemia, including genetic counselling. (5) To encourage parents to use their own resources for self-health care.

In a few cases it was necessary to refer a family for more detailed assessment to the department of psychological paediatrics and to recommend individual counselling or psychotherapy of parents and the child.

The psychiatric team contributed greatly by collaborating closely with the medical and nursing staff and helping them to understand the complex inter-relationships of the biological, social, and psychological needs of the sick children and their families. The medical and nursing staff become more aware of their own reactions and feelings towards the complex needs of these families.

\section{Results}

During the 3-year period of this work the atmosphere in the transfusion department has become less charged, parents and children seem more relaxed, and there has been friendly co-operation with the medical and nursing staff. Parents are able to identify and clarify some of their feelings about the illness, and consequently their anxiety and guilt have been alleviated. We believe that in several cases we succeeded in breaking into the vicious circle and thereby helped the family to maintain better relationships. Similarly some parents and children were able to adopt a more realistic approach to the illness and plan the future. The working relationship between the child psychiatry team, the paediatricians, and the nursing staff has improved. We have now started group therapy with the children. The request came from the children themselves and there are now two groups with adolescents up to age 15 years.

\section{Conclusions and recommendations}

The need for psychosocial support of these families is imperative and it is necessary to provide a more comprehensive management of the child with thalassaemia that includes the somatic and psychosocial aspects of the condition. The same approach is also applied by others in thalassaemia (P Massallia et al., 1981, personal communication) as well as in other chronic or fatal conditions. ${ }^{6}{ }^{7}$ Liaison psychiatry is also an important concept and if suitably 
applied can promote the total management of the chronically sick child. It also seems that more research is needed in relation to the psychosocial aspects of the problem. Our own research programme aims at investigating in greater depth the psychological problems of children aged between 7 and 11 years by using a battery of psychological tests and semistructured interviews. Recent improvements in the prognosis of thalassaemia should be taken into consideration and a great effort should be directed at informing society in general and the authorities in particular so that attitudes may be changed for thalassaemic patients, so that with proper medical treatment and psychosocial management they can cope better with the problems generated by their illness, and live useful and happy lives.

\section{References}

1 Rainbault G. Psychological problems in the chronic nephropathies of childhood. In: Anthony E J, Koupernik $\mathrm{C}$, eds. The child in his family: children at psychiatric risk. London: Wiley, 1973: 65-74.
2 Maxwell G M, Gane S. The impact of congenital heart disease upon the family. Am Heart $J 1969$; 64: 449-54.

3 Leiken S, Hassakis P. Psychological study of parents of children with cystic fibrosis. In: Anthony E J, Koupernik $\mathrm{C}$, eds. The child in his family: the impact of disease and death. London: Wiley, 1972: 49-58.

- Wiener J M. Reactions of the family to the fatal illness of a child. In: Schoemer B, Carr A, Peretz D, Kutscher A, eds. Psychological management in medical practice. New York: Columbia University Press, 1970: 87-101.

5 Gordon N B, Kutner B. Long-term and fatal illness and the family. J Health Hum Behav 1965; 6: 190-6.

- Knudson A G, Jr, Natterson J M. Participation of parents in the hospital care of fatally ill children. Pediatrics $1960 ; 26$ : 482-90.

7 Satterwhite B, Belle-Isle J, Conradt B. Parent groups as an aid in mourning and grief work. In: Olle J, Sahler Z, eds. The child and death. St Louis: Mosby, 1978:211-8.

Correspondence to Dr J Tsiantis, Department of Psychological Paediatrics, 'Aghia Sophia' Children's Hospital, Athens 617, Greece.

Received 15 March 1982 